\title{
DESIGN E INOVAÇÃO NO APROVEITAMENTO SUSTENTÁVEL DE RESÍDUOS EM EMPRESA DE PAPELÃO: reaproveitamento de aparas com melhor valor agregado
}

\author{
Dalton Luiz Razera \\ Prof. Doutor do Programa de Pós-Graduaçāo em Design Universidade \\ Federal do Paraná, Chefe do Setor de Ciências Humanas, Dep. de Artes \\ daltonrazera@ufpr.br \\ Jair Mello Jarek \\ Mestrando do Programa de Pós-Pós Graduaçāo em Desing Universidade \\ Federal do Paraná -UFPR, Brasil. Graduação em Design de Produto. \\ jarekjair@yahoo.com
}

Resumo: Este trabalho mostra os experimentos realizados com resíduos resultantes da fabricação de caixas de papelão. Esses resíduos chamados aparas são geralmente vendidos pelas empresas de cartonagem para serem reciclados por terceiros por uma fração do valor da matéria prima original, o papelão. Por meio de ensaios de compressão em moldes de alumínio empregou-se a tecnologia de compósitos ao relizar a união das aparas com adesivo e também manter a reciclabilidade. Procurou-se analisar as características das aparas durante o processo proposto e o comportamento e qualidades do material após os ensaios. O resultado dos ensaios foi a encontrado na possibilidade de um novo produto orientado ao uso como acessório em embalagens de transporte e aumentar o valor agregado. Em destaque, para as aparas com menor compressão, encontrou-se no uso como isolamento à choques internamente das embalagens no transporte, e no caso das aparas com maior compressão, a possibilidade de modulação como berços customizados e resistência para proteger diferentes tamanhos de produtos e proporcionar estabilidade dentro da caixa durante o transporte. A proposta mantem o material do produto com os mesmos componentes do papelão ondulado e possibilita o descarte integrado ao ciclo existente de coleta e reciclagem do próprio papelão.

Palavras-chave: Sustentabilidade, Embalagens de Transporte, Resíduos de Papelão. 


\begin{abstract}
This paper presents the experiments produced with residues resulting from cardboard manufacturing boxes. Those residues, called usually scraps are sold by the cardboard boxes producers, to be recycled by third part companies by a small fraction of the original raw material price. Through practical essays of compression methods, based on composites technology, two materials (card board scraps and adhesive), are bonded together using aluminum cast molds. The analysis of the scraps carachetristics after this process about its behavior and qualities as a product was the main goal. As a considerantion other material qualities as a new product to be used like an accessory inside transport package. For the scraps molded under lower pressure coud be delivery for insulation against shocks. Otherwise for scraps molded under higher pressure could be delivery as customized craddles to mantain products instability inside the box.
\end{abstract}

Keywords: Sustainability, Transport Package, Cardboard Residues.

\title{
1. INTRODUÇÃO
}

A melhoria na relação das empresas com o meio ambiente pode otimizar a produtividade dos recursos utilizados, com benefícios diretos na economia de matériaprima e insumos resultantes do processamento mais eficiente na substituição, reutilização ou reciclagem, menor consumo de água, redução do custo de atividades envolvidas no manuseio, transporte e descarte de resíduos, (COELHO et al., 2011).

A proposta desta pesquisa de aproveitamento de resíduos de embalagens de papelāo é uma continuação do estudo de iniciaçāo científica conduzido pelo Departamento de PPDesign - UFPR, (RAZERA e SCHUSTER, 20090). Este artigo descreve o experimento de moldagem por compressāo de aparas recolhidas das sobras de fabricaçāo de embalagens de papelão ondulado (PO). A proposta adiciona um novo processo e analisa as características e qualidades apresentadas pelas aparas no uso em embalagens de transporte (Macedo e Valença, 1995).

$\mathrm{Na}$ pesquisa foram identificados dois tipos de empresas do setor de embalagens com material residual e volumes contínuos em relação ao ciclo de reciclagem, Figura 1; 


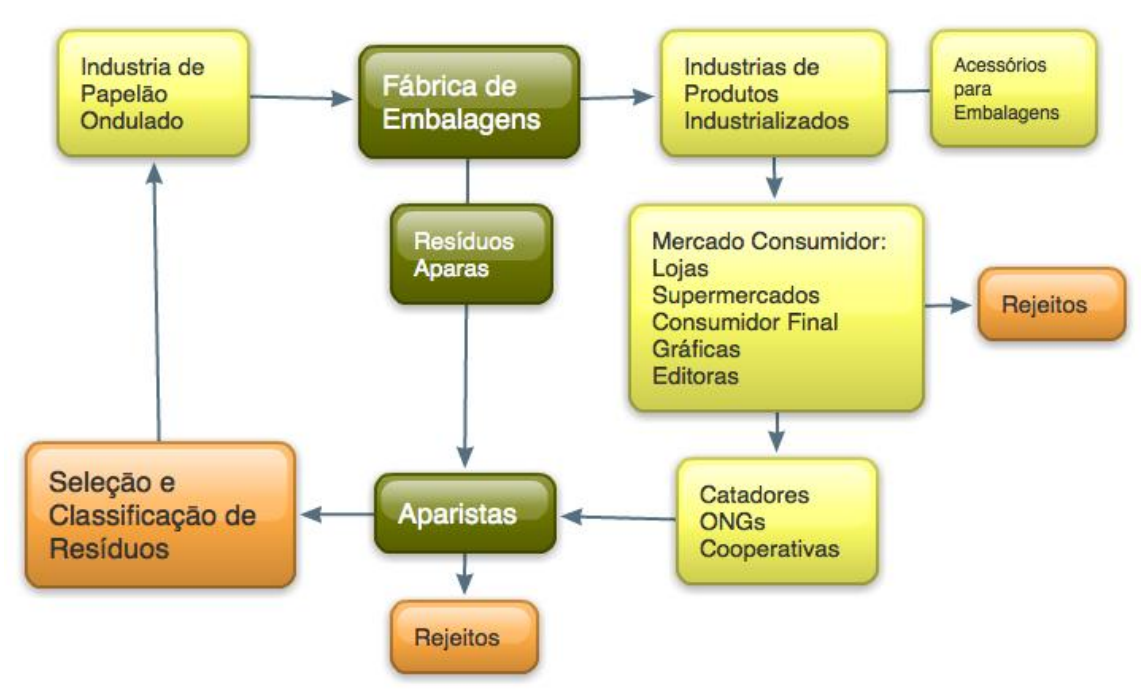

Figura 1 - reciclagem de aparas de papelão. Fonte: modificado pelo autor.

1. Indústrias fabricantes de PO, apresentam um ciclo fechado, fabricam celulose, papel Kraft, chapas de papelão ondulado, e embalagem de caixas rígidas. Na reciclagem as aparas são transformadas em papelão reciclado pela própria empresa, sem necessidade do uso de terceiros, utilizado na confecção do miolo (onda) do papelão ondulado, também agregam cerca de $20 \%$ de PO reciclado coletado externamente e pré-selecionado.

2. Fábricas de embalagens ou empresas de cartonagem, ciclo aberto: fabricam caixas padrão produzidos em máquinas de corte e vinco com ângulos ortogonais que geram "aparas" de chapas pré-cortadas de PO. As chapas são compradas em tamanhos padrão diretamente das indústrias de papelão. As aparas são recicladas através de terceiros, empresas chamadas aparistas que compram as aparas por $12 \%$ do valor por quilo da matéria prima utilizada original. A empresa de cartonagem Embrart, localizada em Curitiba no sul do Brasil, usada como um recorte dos dados do setor, produz cerca de 3,5\% de aparas de uma produção mensal aproximada de 600 toneladas de chapas de papelão ondulado (PO) ou 21 toneladas, em embalagens de transporte, Figura 2.

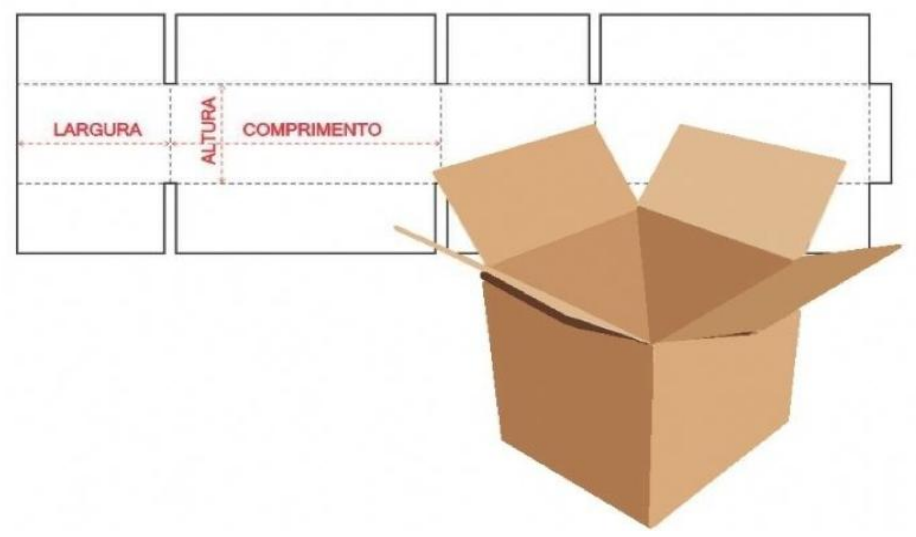

Figura 2 - caixas de transporte de PO. Fonte: elaborado pelo autor. 
Após visitas à empresa Embrart, selecionou-se aparas resultantes da fabricação das caixas de PO da linha "normal" para uso nos ensaios por serem as mais homogêneas em relação ao tamanho (média de $15 \times 1 \mathrm{~cm}$ ), e frequência na produção, Figura 3.

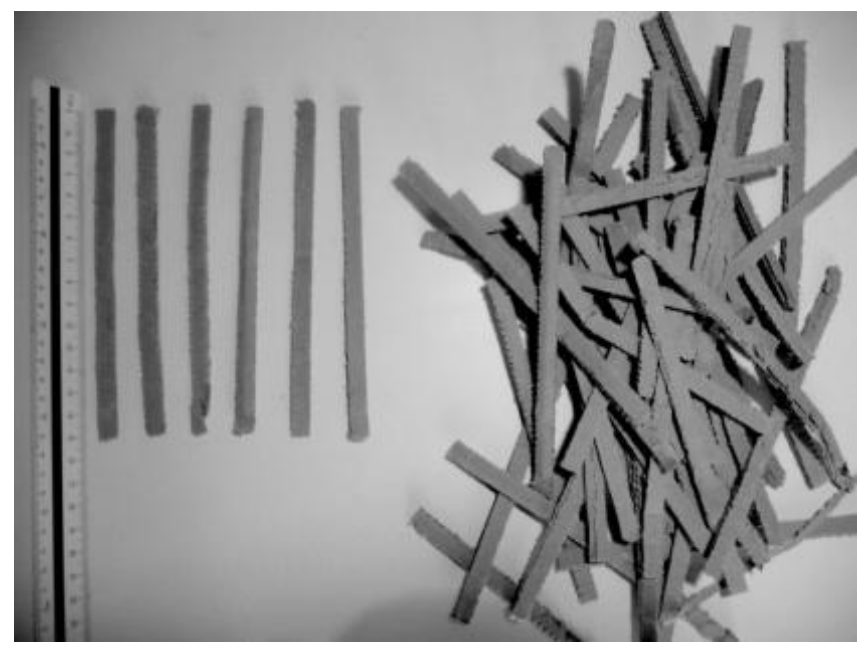

Figura 3 - aparas de papelão ondulado. Fonte: elaborado pelo autor.

O objetivo do estudo foi propor o uso de uma tecnologia de baixa complexidade baseada em compósitos de fibras e papel com a compressão em série das aparas com adesivo utilizado para fabricação do PO (amido de mandioca), facilmente reciclável com o material das caixas. Nos ensaios, para facilitar o manuseio, foi utilizado adesivo PVA a base de água, (RAZERA, 2009).

As aparas, material que se comporta como reforço, com as fibras em configuração aleatória, foram primeiramente impregnadas com adesivo, a matriz contínua, que envolve o reforço, Figura 4.
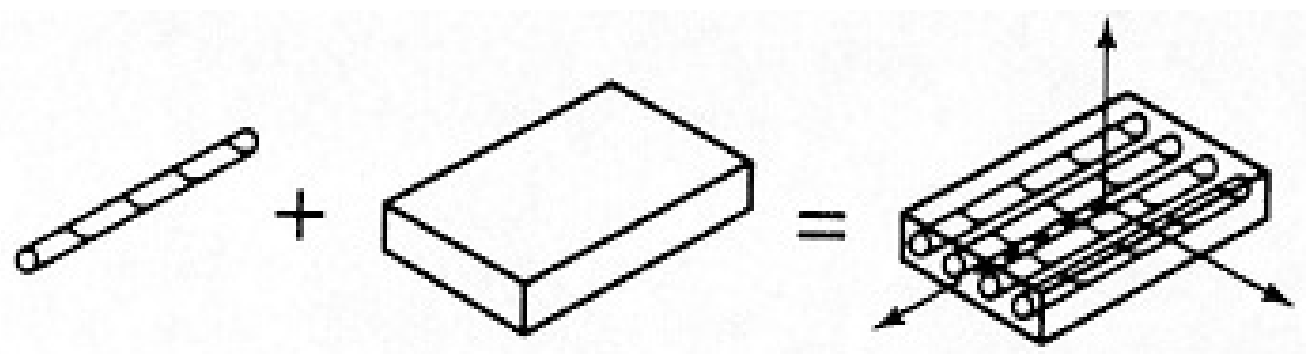

Figura 4 - configuração do compósito. Aparas como reforço + adesivo homogêneamente distribuido = compósito a ser moldado. Fonte: alterada pelo autor. 
Após o material ser preparado os ensaios foram prensados a quente em moldes de alumínio fundido, Figura 5.

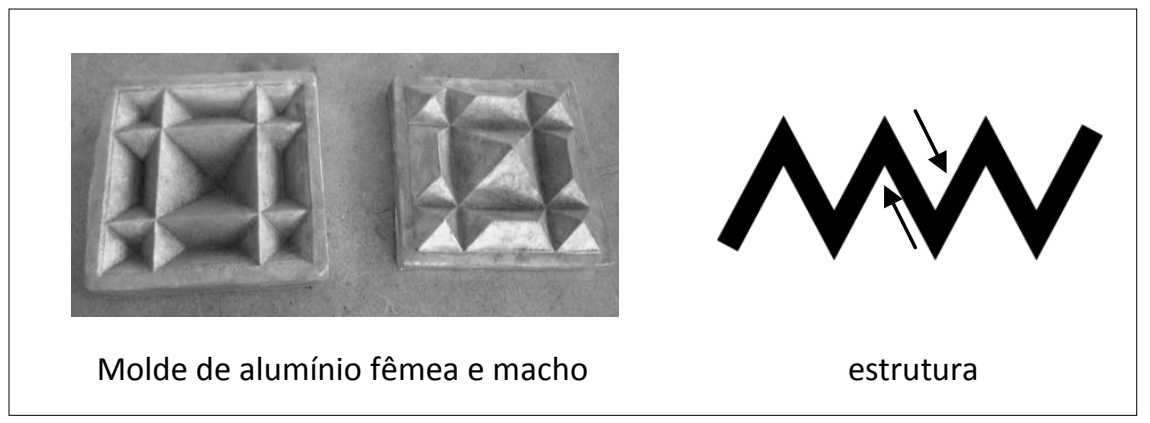

Figura 5- molde de alumío para compressão das aparas. Fonte: elaborado pelo autor

O resultado obtido com o colchão de aparas após a prensagem evidenciou o design da estrutura tridimensional do molde, definidas como áreas de acolchoamento, onde os ângulos opostos tentam anular os choques na movimentação dentro da embalagem. O molde foi preparado a partir do design de um módulo para compor uma malha que pudesse ser reproduzido em escala e quantidades posteriormente. Esse molde foi finalizado em alumínio para resistir a compressão e temperatura de secagem durante os ensaios.

As linhas de compressão ajudaram na orientação da flexão das aparas. A malha quadrada manteve a flexibilidade procurada. 0 ângulo das figuras foi determinado pela maior possibilidade de dobras, desmoldagem na fabricação e distribuição das tensões durante o emprego do material para proteger produtos no transporte.

Essas aparas foram então impregnadas com adesivo termoplástico, semelhante ao adesivo utilizado originalmente na produção das chapas de papelão, e prensadas contra o molde de alumínio medindo $14 \times 14 \mathrm{~cm}$ representando um módulo teste, com pressão controlada variando de 3 a 4 toneladas pela área do molde. 0 uso de estufa com temperatura de 80 graus ajudou a acelerar a secagem e manter o material na espessura desejada, Figura 6.
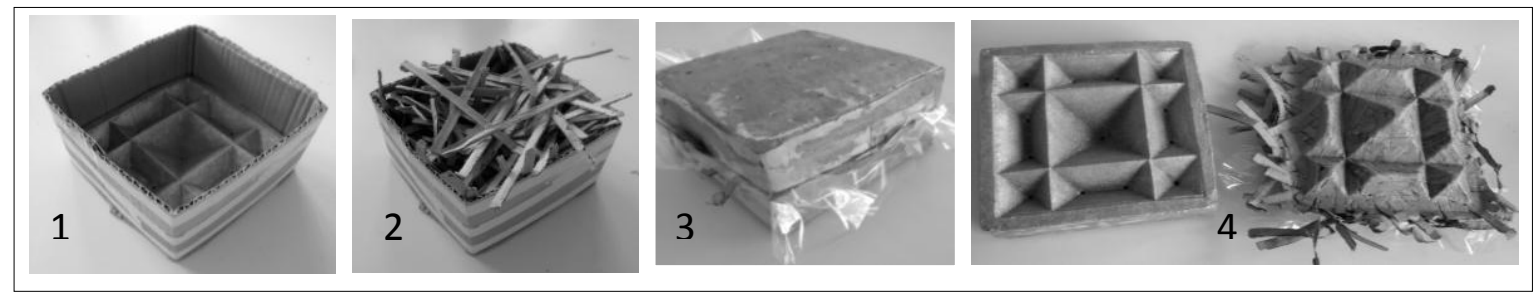

Figura 6 - procedimentos dos ensaios: 1 molde alumínio com caixa formadora, 2 aparas impregnadas de adesivo sobre molde fêmea, 3 molde macho e fêmea com desmoldante de papel celofane, 4 desmoldagemFonte: elaborado pelo autor 


\section{DESENVOLVIMENTO}

A pesquisa direcionou as caracteristicas e propriedades buscadas nas funções básicas de embalagens de transporte vendidas pela empresa: proteção no manuseio, leveza e resistência no transporte e estocagem dos produtos, como os principais focos à ser buscado neste novo produto. As variáveis trabalhadas nos ensaios foram: quantidade e densidade das aparas (gr); a porcentagem de adesivo (ml); a pressão utilizada na compressão das aparas no molde de alumínio $\left(\mathrm{kg} / \mathrm{cm}^{2}\right)$; a temperatura na compressão - para acelerar a secagem; o tempo de secagem do adesivo (min.), importante para a viabilidade do processo e ainda facilitadores da retirada da peça do molde, como desmoldante e uma caixa formadora para melhor direcionar a colocação do material no molde, Tabela 1.

Tabela 1 - Variáveis de ensaios com molde de alumínio e aparas de PO.

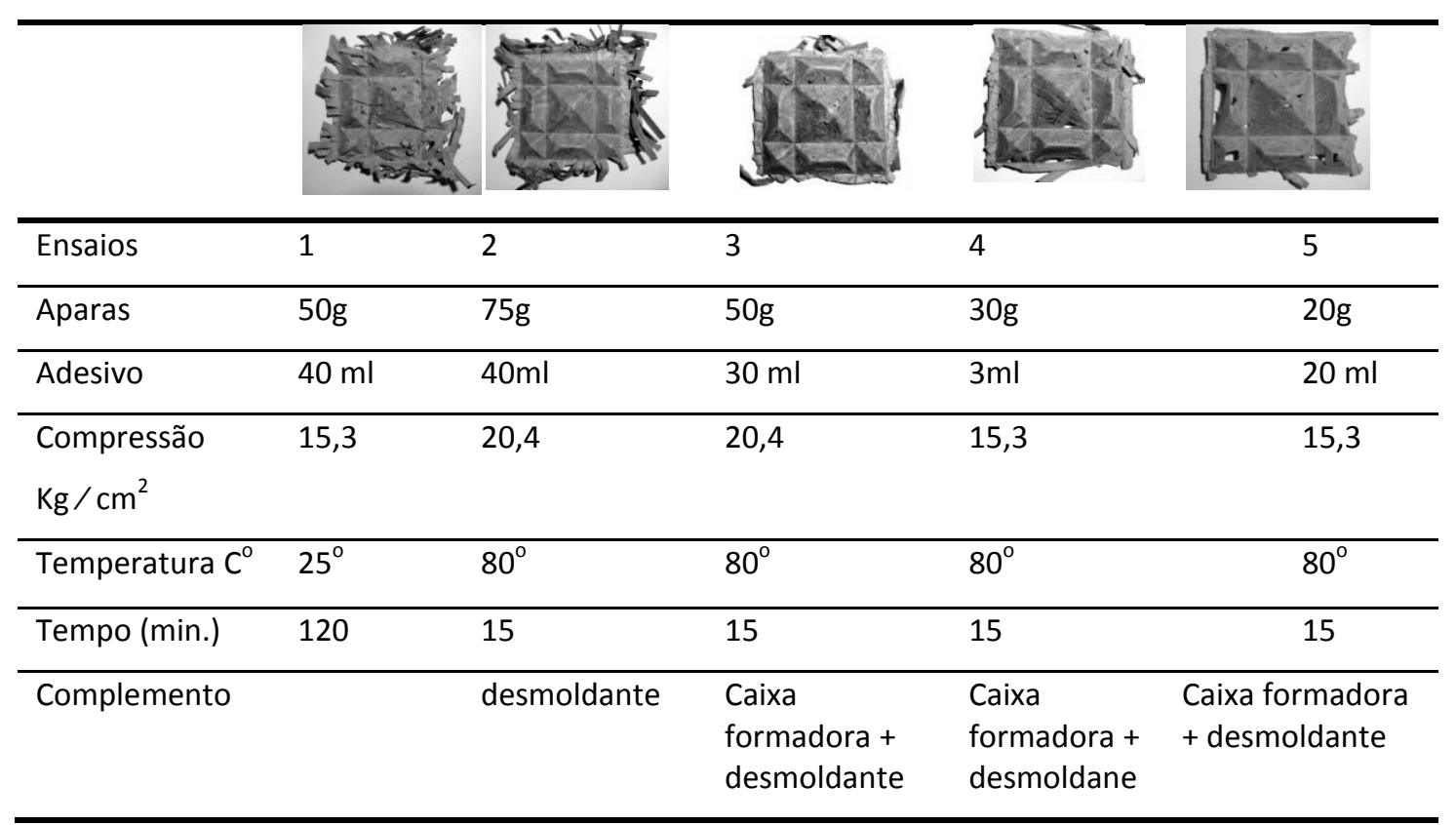

Fonte - Elaborado pelo autor com base na pesquisa realizada.

O peso específico do produto foi produzido comparando-se diferentes amostras com a combinação entre o peso das aparas (material seco e classificado por tamanho) e a quantidade de adesivo, para chegar ao peso mínimo, mas que mantivesse a integridade e resistência do material após moldado. $\mathrm{O}$ adesivo utilizado para encolamento variou de 40 a $20 \mathrm{ml}$ com a progressāo dos experimentos, foi adotado a diluição de $50 \%$ de água. A aspersāo do adesivo nas aparas foi feita com uma pistola de ar comprimido localizada no interior de uma encoladeira, que ao girar proporciona a dispersāo do adesivo por todas as faces das aparas.

Este trabalho foca na criação de um produto mantendo o processo de fabricação dentro da própria empresa com o aproveitamento dos resíduos resultantes da fabricação das embalagens, evitando que sejam revendidos a baixo custo para empresas aparistas. A proposta então, se manteve dentro do mercado de embalagens em que a empresa atua, mas oferece uma opção inovadora de serviço pela empresa como diferencial para seus clientes e possibilidade de manter o preço acessível. A reciclagem, após o uso do produto, dentro do mesmo ciclo das caixas de papelão 
consequentemente pode diminuir a quantidade de resíduos dentro da empresa e melhorar o valor para os catadores deste material, figura 7.

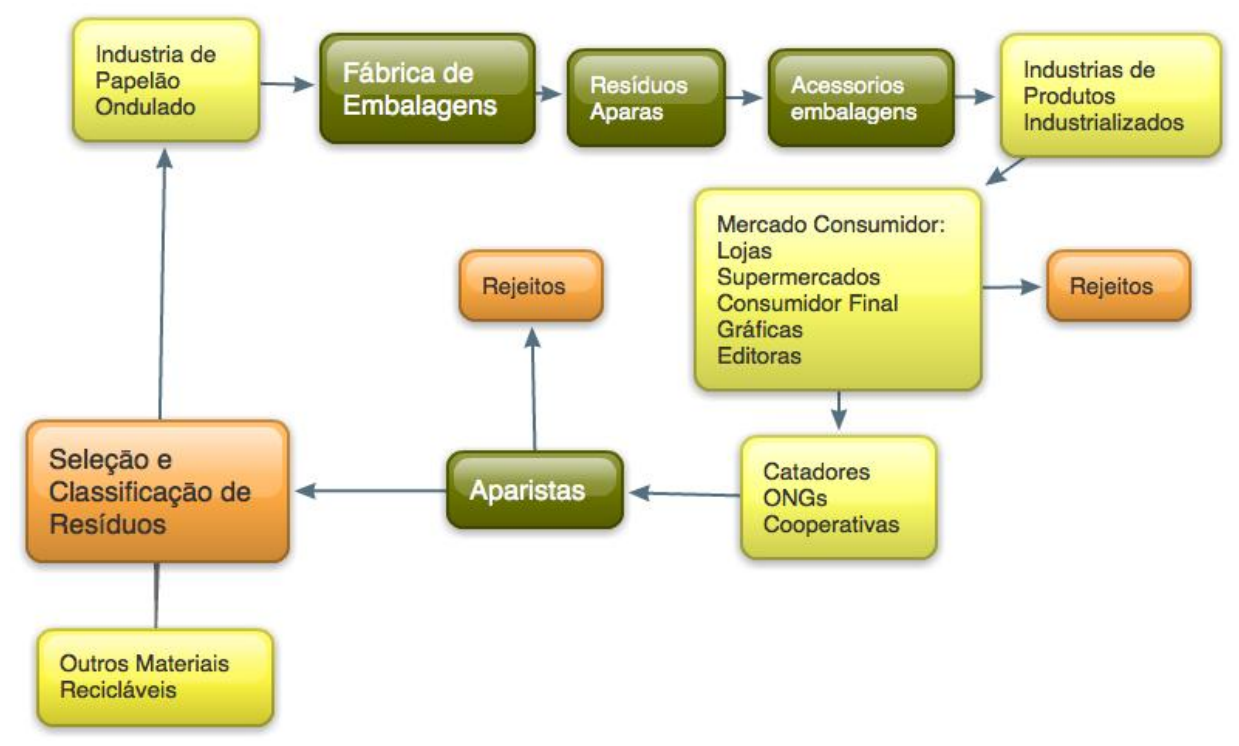

Figura 7 - ciclo de aproveitamento das aparas dentro das fabricas de embalagens. Fonte elaborado pelo autor.

O aproveitamento das aparas como um produto altera o ciclo dos resíduos convencional, mas introduz um novo ciclo onde a fábrica de embalagens dispõe aos fabricantes de produtos industrializados um acessório para as embalagens. Também, segundo entrevistas realizadas dentro da empresa Embrart, com possibilidade de agregar maior valor ao as aparas como um produto.

\section{CONCLUSÃO}

Os ensaios mostraram possibilidades de criação de várias linhas de produtos, utilizando-se somente as aparas e adesivo para sua união em um compósito. Estes diferentes conceitos foram demonstrados pelas variações quantitativas das principais variáveis propostas neste trabalho: densidade das aparas por $\mathrm{cm}^{2}$ - peso em gramas; quantidade de adesivo - em mililitros; e compressão na moldagem $-\mathrm{kg} / \mathrm{cm}^{2}$. Os resultados dos ensaios demostraram a possibilidade de uso em dois grupos de acessórios para embalagens: como calços e berços pré moldados quando a compressão e densidade for de $20 \mathrm{~kg} / \mathrm{cm}^{2}$ ou maior; e como preenchimento e proteção alcochoada contra choques quando usada compressão menor que $15 \mathrm{~kg} / \mathrm{cm}^{2}$ resultando menor densidade.

A proposta ainda demonstrou conceitos importantes associados as embalagens de transporte ao procurar aproveitar os resíduos da fabricação de embalagens de papelão: diminuir o custo e a movimentação dos resíduos ao manter o processamento da reciclagem dentro da empresa; aumentar o valor agregado dos resíduos 
transformando-os em um produto comercial; facilitar a armazenagem com um design que possibilita o empilhamento; manter-se dentro do ciclo de reciclagem do papelão ondulado; ter baixo peso com boa resistência para proteger o produto transportado.

A fabricação de um produto com as aparas depende do desenvolvimento de maquinário apropriado, mas com tecnologia existente.

\section{SUGESTÕES}

- Estudar, para trabalhos posteriores, processos industriais que possam ser utilizados para transformar todos os resíduos da fabricação de caixas em tamanhos homogêneos ideais para um processo de aproveitamento em novos produtos.

- A introdução em linha de produção de um produto novo demanda pesquisa mercadológica antes de seu lançamento. Esse é um processo que deve envolver varias áreas como: engenharia de produção; marketing; engenharia de materiais, etc. Desta forma o designer posiciona-se como guia para novas tendências e propostas.

- Propor novos desenhos de malhas para produtos com outras dimensões e proporções diferentes, com a intenção de ampliar o uso em outras áreas: construção civil, marcenaria, mobiliário, embalagens, divisórias, etc.

- Propor o estudo de dimensões e formas customizadas para serem utilizados como calços em embalagens de transporte para produtos específicos.

\section{REFERÊNCIAS}

COELHO, H. M. G., LANGE, L. C., JESUS, L. F. L., SARTORI, M. R. Proposta de um Índice de Destinaçāo de Resíduos Sólidos Industriais. Engenharia Sanitária Ambiental, v.16, n.3, p. 307-316, 2011.

CEMPRE - Compromisso Empresarial para Reciclagem. Ficha Técnica -Papel Ondulado. Disponível: http://www.cempre.org.br/servicos_mercado.php Acesso em: 24/10/2012

MACEDO, A.R.P., VALENÇA, A.C. de V. Reciclagem de Papel-Papel e Celulose. BNDES, p.20. 1995.

RAZERA, D.L., Estudo sobre as Interações entre as variáveis do processo de produção de painéis aglomerados e produtos moldados de madeira. Tese Doutorado Ciências Florestais Universidade Federal do Paraná, 2006.

RAZERA, D. L.; SCHUSTER, E. Seleção de Materiais de Baixo Impacto: aplicação de compósitos moldados a partir de aparas de papelão ondulado em embalagem para eletrodoméstico. Programa de Pós-Graduação em Design da UFPR, 2009. 